\title{
Correction to: A robust image steganography based on the concatenated error correction encoder and discrete cosine transform coefficients
}

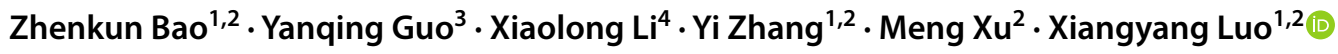

Published online: 27 June 2019

๑) Springer-Verlag GmbH Germany, part of Springer Nature 2019

\section{Correction to: \\ Journal of Ambient Intelligence and Humanized Computing \\ https://doi.org/10.1007/s12652-019-01345-8}

The article "A robust image steganography based on the concatenated error correction encoder and discrete cosine transform coefficients" written by Zhenkun Bao et al. was originally published electronically on the publisher's internet portal (currently SpringerLink) on 11 June 2019 with open access.

With the author(s)' decision to step back from Open Choice, the copyright of the article changed on June 2019 to (C) Springer-Verlag GmbH Germany, part of Springer Nature
2019 and the article is forthwith distributed under the terms of copyright.

Publisher's Note Springer Nature remains neutral with regard to jurisdictional claims in published maps and institutional affiliations.

The original article can be found online at https://doi.org/10.1007/ s12652-019-01345-8.

Xiangyang Luo

luoxy_ieu@sina.com

1 State Key Laboratory of Mathematical Engineering and Advanced Computing, Zhengzhou 450001, China

2 Zhengzhou Science and Technology Institute, Zhengzhou 450001, China

3 School of Information and Communication Engineering, Dalian University of Technology, Dalian 116024, China

4 Institute of Information Science, Beijing Jiaotong University, Beijing 100044, China 